\title{
ANALISIS NILAI ETIKA TOLONG-MENOLONG TOKOH HEPI DALAM NOVEL ANAK RANTAU KARYA A. FUADI
}

\author{
Selfi Maikomah ${ }^{13}$, \\ Erlina Zahar ${ }^{14}$, Harbeng Masni ${ }^{15}$
}

\begin{abstract}
The purpose of this study is to describe the ethical value of the help of the Hepi character in Son Rantau novel by A. Fuadi. This research includes descriptive research type which is qualitative. Primary data in this research is in the form of written data in the form of sentences, words, and paragraphs in the form of dialogs and monologues contained in Hepi characters in novels Anak Rantau A. Fuadi, while secondary data in this study in the form of books and literature taken from the library where the theories relate to this research. Based on the results of this study it can be concluded that the value of the helpful ethics contained in the novel Rantau Son of A. Fuadi there are 24 quotations are all reinforced also by exposure to dialogue and monologue. This illustrates this novel put forward that people live in society is needed each other to help each other in order to create prosperity help-help is necessary in living life because human life must be socialized and interdependent with each other
\end{abstract}

Keywords: Value, ethics, novel

\footnotetext{
${ }^{13}$ Mahasiswa Program Studi Pendidikan Bahasa dan Sastra Indonesia Universitas Batanghari

${ }^{14}$ Dosen Program Studi Pendidikan Bahasa dan Sastra Indonesia Universitas Batanghari

${ }^{15}$ Dosen Program Studi Pendidikan Bahasa dan Sastra Indonesia Universitas Batanghari 


\section{PENDAHULUAN}

Karya sastra sebagai sarana yang menarik untuk dibaca karena karya sastra sebagai ungkapan perasaan manusia."Karya sastra adalah ungkapan pribadi manusia yang berupa pengalaman, pemikiran, perasaan, ide, semangat, keyakinan dalam suatu bentuk gambaran konkret yang membangkitkan pesona dengan alat bahasa" (Sumardjodalam Rohmansyah, 2014:2). "Karya sastra adalah karya imajinatif atau fiktif yang bermedium bahasa dan mempunyai nilai estetik yang tinggi. Acuan karya sastra bukanlah dunia nyata, melainkan fiksi dan imajinatif. Pernyataan-pernyataan karya sastra bukanlah proposisi yang logis dan karakter-krakter dalam karya sastra bukanlah tokoh-tokoh sejarah dalam kehidupan nyata". (Wellek dalam Dewajati, 2015:1). Karya sastra dapat memberikan sejuta makna "Karya sastra adalah karya kreatif dan bermediumkan bahasa yang tidak absolud" (Susanto, 2016:7). Karya sastra adalah karya imajinatif atau fiktif yang bermedium bahasa dan mempunyai nilai estetik yang tinggi. Hal-hal yang terdapat dalam karya sastra bukanlah dunia nyata, melainkan fiksi dan imajinatif. Pernyataan-pernyataan dalam karya sastra bukanlah proposisi yang logis dan karakter-krakter dalam karya sastra bukanlah tokoh-tokoh sejarah dalam kehidupan nyata.

Karya Sastra tidak seperti halnya ilmu kimia atau sejarah, tidaklah menyuguhkan ilmu pengetahuan dalam bentuk jadi. Sastra berkaitan erat dengan sesama aspek manusia aspek manusia dan alam dengan keseluruhanya. Setiap karya sastra selalu menghadirkan sesuatu yang kerap menyajikan banyak hal yang apabila dihayati benar-benar akan menambah pengetahuan orang yang menghayati (Rahmanto, 1988: 13).

Karya sastra memiliki beberapa jenis salah satunya prosa yang berbentuk novel. Novel adalah cerita mengenai salah satu episode dalam kehidupan manusia, suatu kejadian yang luar biasa dalam kehidupan itu, sebuah krisis yang memugkinakn terjadinya perubahan nasib pada manusia (Jassin dalam Antilan 2012: 62). Novel sebuah cerita rekaan yang menampilkan serangkaian peristiwa. "Novel adalah prosa rekaan yang panjang yang menyuguhkan tokoh-tokoh dan menampilkan serangkaian peristiwa dan latar secara tersusun" (Sudjiman 1990: 54).

Novel adalah sebuah karya sastra yang didalamnya terdapat unsur-unsur pembangun. "Novel adalah jenis prosa yang mengandung unsur tokoh, alur latar, rekaan yang menggelarkan kehidupan manusia atas dasar sudut pandang pengarang, dan mengandung nilai hidup, diolah dengan teknik kisahan dan ragaan yang menjadi dasar konvensi penulisan" (Zaidan, 1990: 54). Dari pendapat Zaidan di atas menggambarkan bahwa novel merupakan sebuah karya fiksi yang memiliki unsur-unsur pembangun yang di dalamnya terdapat nilai-nilai kehidupan yang tergambar di tengah masyarakat.

Novel juga terdapat unsur instrinsik dan unsur ekstrinsik. Unsur ektrinsik dalam novel mengandung nilai-nilai kehidupan salah satuanya 
nilai etika. "Nilai etika adalah sebagai ilmu yang mempelajari tentang segala sesuatu kebaikan dalam hidup manusia semuanya, mengenai gerak gerik pikiran dan perbuatan seseorang. melainkan membahas tentang sifat-sifat dasar. Jadi etika menggunakan refleksi dan metode pada tugas manusia untuk menemukan nilai-nilai itu sendiri ke dalam etika dan menerapkan pada situasi kehidupan konkrit" (Abdullah, 2006: 5). Abdulah berpendapat di dalam nilai etika terdapat etika tolong-menolong. "Etika Tolong menolong ialah sikap yang senang menolong orang lain, baik dalam bentuk material atapun tenaga dan moral" (Abdullah, 2006: 368). Tolong menolong dalam lingkungan masyarakat sangat penting. Seseorang hidup di dalam lingkungan masyarakat wajib tolong-menolong apabila seseorang mempunyai hubungan kemanusiaan. bentuk dari tolong menolong dalam masyarakat bisa berupa material, tenaga dan moral..salah satu novel yang banyak mengandung nilai etika tolongmenolong adalah novel Anak Rantau karya A. Fuadi. novel Anak Rantu karya A. Fuadi banyak mendapatkan tanggapan yang positif dari pembaca. Novel ini mengedepankan nilai etika tolong-menolong yang mengisahkan seorang anak yang bernama Hepi memiliki nilai etika tolong-menolong yang baik terhadap orangtuanya, teman-temanya, dan masyarakat disekitarnya. Tokoh Hepi membuat pembaca akan terbawa pada kenyataan prilaku seseorang dimasyarakat. Nilai etika tolongmenolong tokoh Hepi dapat dijadikan pandangan kehidupan prilaku masyarakat. Novel ini dapat menumbuhkan kesadaran bahwa dalah kehidupan bermasyarakat kita perlu bantuan orang lain utuk melakukan sesuatu sudah sepantasnya kita sesama mahluk hidup untuk hidup saling tolongmenolong.

Novel Anak Rantau karya A. Fuadi terbit pada tahun 2017. Novel masih bisa dibilang novel baru namun cerita yang disajikan dalam novel ini kental akan nilai etika tokoh yang diperankan oleh Hepi. Suasana di kampung duku yang Hepi tinggali tidak pernah lepas dari nilai etika.

Pengaruh globalisasi banyak mempengaruhi pola pikir masyarakat saat ini. Masyarakat banyak cenderung individualis dan lebih memikirkan kebutuhan sendiri tanpa memikirkan orang-orang di sekitarnya. Padahal setiap manusia merupakan mahluk sosial yang membutuhkan bantuan orang lain. Kurangnya sikap tolong-menolong dapat menimbulkan sifat masa bodoh dan tidak mau lagi perduli dengan apa yang terjadi disekitarnya baik keluarga, tetangga, sahabat. Akibatnya berdapak pada masyarakat contohnya korupsi. Korupsi disebabkan para koruptor tidak memiliki rasa perduli pada rakyat, sehingga dia tega memakan uang rakyat yang seharusnya dapat meringankan beban rakyatnya. Berdasarkan fenomena sosial di atas penulis ingin memaparkan nilai etika tolong-menolong tokoh Hepi dalam novel Anak Rantau karya A. Fuadi. Novel ini banyak mengandung nilainilai postitif yang dapat diambil oleh pembaca. selain itu, penulis juga 
tertarik dengan cerita yang disaikan oleh pengarang.

Kajian mengenai karya sastra khususnya novel sudah pernah diteliti oleh peneliti lain. Skripsi mahasiwa Stani Kusuma Lestari dari Universitas Sebelas Maret Surakarta. Dengan judul penelitian Studi Analisis Wacana Penerapan Etika Moral pada Program Liputan 6 Petang Surya Citra Televisi (SCTV). Skrpsi mahasiwa Diyah Retno Astrini dari Universitas Muhamadiyah Malang dengan judul penelitian Nilai-Nilai Moral dalam Tokoh Utama dalam Novel Perahu Kertas Karya Dewi Lestari. Skripsi mahasiswa Gunawan dari Universitas Batanghari Jambi dengan judul penelitian Analisis Nilai Etika Tokoh Keenan dalam Novel Perahu Kertas Karya Dewi Lestari. Skripsi mahasiswa Rehnah Nainggolan dari Universitas Batanghari Jambi dengan judul penelitian Analisis Nilai Etika Terhadap Tokoh Keke dalam Novel Surat Cinta Untuk Tuhan karya Agnes Davona. Berdasarkan hasil penelitian yang telah dilakukan. Penelitian ini tidak jauh berbeda dengan penelitian sama yang dilakukan peneliti lain namun, ada perdedaan antara objek dan subjek penelitian. Berdasarkan latar belakang masalah di atas, Penelitian ini bertujuan untuk mendeskripsikan nilai etika tolong-menolong tokoh Hepi dalam novel Anak Rantau karya A.Fuadi.

Adapun manfaat dalam penelitian ini yaitu (1) Bagi pembaca karya sastra, sebagai tambahan ilmu dalam memahami nilai etika hubungan manusia dengan masyarakat tokoh Hepi dalam novel
Anak Rantau karya A. Fuadi. (2) Bagi sastrawan, sebagai landasan dasar dalam mengangkat nilai etika tolongmenolong dalam karya sastra khususnya novel. (3) Bagi penulis yang selanjutnya, penelitian ini dapat dijadikan sebagai bahan acuan untuk penelitian yang akan melakukan penelitian yang sama.

\section{METODE PENELITIAN}

Jenis Penelitian yang digunakan deskriptif yang bersifat kualitatif. deskriptif merupakan menggambarkan dari suatu objek yang akan dianalisis oleh penulis. "Deskriptif merupakan prosedur pemecahan masalah yang diselidiki dengan mendeskripsikan atau melukiskan keadaan subjek atau objek penelitian (novel) pada saat sekarang berdasarkan fakta-fakta yang tampak atau sebagaimana adanya" (Siswantoro, 2010: 56). Selain itu penelitian ini juga menggunakan pendekatan kualitatif.

Subjek dalam penelitian ini adalah novel Anak Rantau karya A. Fuadi, sedangkan objek dalam penelitian ini adalan nilai etika tolong-menolong tokoh Hepi dalam novel Anak Rantau karya A. Fuadi. Teknik pengumpulan data merupakan cara penulis mengumpulkan suatu data yang digunakan dalam penelitian. "teknik pengeumpulan ada merupakan bagian penting dalam dari proses penelitian. Begitu sentral peran-peran pengumpulan data sehingga kualitas penelitian bergantung padanya" (Siwantiroro, 2010: 73). Teknik pengumpulan data suatu langkah- langkah yang digunakan dalam proses penelitian. Pengumpulan data dalam penelitian 
ini menggunakan dokumentasi dan studi literature yangdifokuskan untuk untuk menganalisis isi dari sebuah novel terutama Nilai etika yang terkaitan dengan hubungan manusia dengan tokoh Hepi dalam novel Anak Rantau karya A. Faudi.

Penelitian sastra merupakan peranan penting yang menyangkut suatu objek penelitian yang didalamnya terkait pemaknaan yang berpengaruh positif terhadap pembinaan dan pengembanagn sastra. "Tujuan dan peranan penelitian sastra untuk memahami makna karya sastra sedalm-dalamnya" (Pradopo dalam Endaswara, 2013:10). Tujuan dalam penelitian karya sastra agar lebih mendalami makna yang terdapat dalam karya sastra secara mendalam.

Teknik pengumpulan data dilakukan beberapa langkah-langkah menurut Refiek, 2010:76) memiliki langkah-langkah sebagai berikut:

1. Membaca keseluruhan cerita terlebih dahulu. Dari pemembacaan ini, diperoleh pengetahuan dan kesan tentang cerita, tentang tokoh-tokohnya, tentang berbagai tindakan yang mereka lakukan, serta berbagai peristiwa yang mereka alami.

2. Apabila cerita terlalu panjang, maka cerita tersebut dapat di bagi menjadi beberapa episode, maka perlu pembacaan ulang terhadap cerita-cerita itu yang lebih seksama lagi untuk memperoleh gambaran yang jelas, yang dapat digunakan sebagai dasar dalam analisis ini.

3. Setiap episode mengandung deskripsi tentang tindakan atau peristiwa yang dialami tokoh dalam cerita.
4. memperhatiakan adanya suatu relasi atau kalimat-kalimat yang menunjukkan hubunganhubungan tertentu antarelemen dalam suatu cerita.

5. Disusun mengikuti sumbu sintagmatik dan pradigmatik. Makna dan elemen mitos tergantung pada relasi sintagmatik dan pradigmatiknya dengan elemen-elemen lain.

6. Menoba menarik hubungan relasi antar elemen-elemen di dalam suatu cerita secara keseluruhan. Langkah ini dimaksudkan untuk mengontrak sebuah makna cerita secara internal yang dapat disimpulkan sebagai suatu bangunan makan.

7. Menarik kesimpulan-kesimpulan akhir dengan mencoba mamaknakan cerita-cerita internal di atas dengan kesimpulankesimpulan referensi atau kontektsual di mana cerita itu berada dan mencoba menarik sebuah makna umum yang menempatkan makna internalitu sebagain dari makna-makna umum secara integral.

\section{HASIL DAN PEMBAHASAN}

Berdasarkan penelitian yang dilakukan, penulis menganalisis tentang nilai etika tolong-menolong tokoh Hepi dalam novel Anak Rantau karya A. Fuadi. Hasil dari penelitian ini diperoleh aspek nilai etika tolongmenolong tokoh Hepi dalam novel Anak Rantau karya A. Fuadi teridentifikasi pada penjelasan di bawah memiliki 24 kutipan disini penulis akan mendekripsikan beberapa kutipan di bawah ini: 
Gambaran nilai etika tolong menolong tokoh Hepi di dalam novel Anak Rantau karya A. Fuadi ini menggambarkan bahwa Hepi suka menolong orang hal ini dapat terlihat dari terdapatnya kutipan-kutipan yang memperlihatkan bahwa Hepi suka menolong keluarganya, temantemanya, tetangganya bahkan kampungnya sendiri hal ini terlihat dari beberapa kutipan diantaranya:

(1.1) Hepi menghambur ke depan. Berteriak keras sembari mengibasngibaskan tangan ke arah Zen yang merasa tidak bersalah "Keluar wa'ang sekarang!". Dia menghardik Zen. Hepi lantas mendekati Ibu Ibet yang masih meggigil berdiri di atas kursi dan mengulurkan tangan untuk membantunya turun (AR: 88)

Kutipan 1.1 menggambarkan Hepi memberikan pertolongan kepada Ibu Ibet yang menggigil ketakutan di atas kursi karena ular kecil hijau yang disimpan Zen di saku celannya. Bentuk tolong-menolong yang dilakukan Hepi terhadap Ibuk Ibet yang sangat takut terhadap ular.

(1.2) Pagi-pagi sekali hari Minggu, saat sedang membuka lapaunya, Mak Tua Ros terkejut melihat tiga bujang ini sudah berdiri menunggu di depan pintu. "Biarlah kami tolong Mak Tuo". Sejak suaminya meninggal tahun lalu, Mak Tuo ini tampak kepayahan mengurus sendiri lapaunya $(A R$ : 91)

Kutipan 1.2 menggambarkan Hepi, Zen dan juga Attar sudah berdiri di depan pintu lapau di pagi hari Minggu. Mak Tuo Ros terkejut ketika Hepi Attar dan Zen tiba-tiba untuk menawarkan diri membantu Mak Tuo Ros yang tampak kepayahan mengurus lapaunya semenjak ditinggal suaminnya. Bentuk tolong menolong yang dilakukan Hepi dan teman-temanya membantu Mak Tuo Ros yang kelelahan menjaga lapau sendirian.

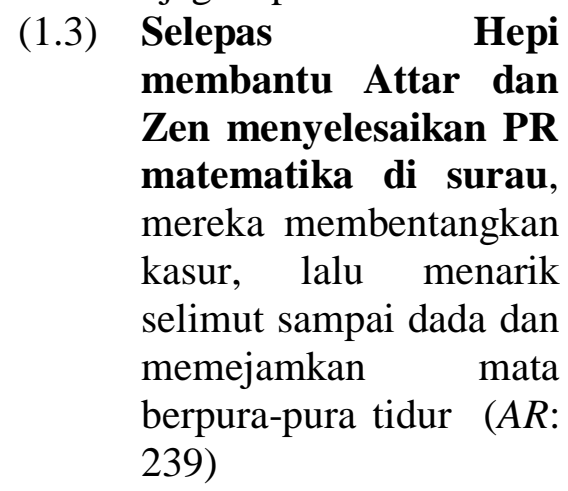

Kutipan 1.3 menggambarkan. Sebelum tidur mereka kerap mengerjakan PR Yang diberikan guru dan ketika Attar dan Zen tidak mengerti Hepi akan membantunya untuk menyelesaikanya. Karena Hepi lebih pintar dibandingkan dengan Attar dan Zen tapi Hepi tidak segansegan menolong Attar dan Zen. Bentuk tolong menolong yang diberikan Hepi ialah ketika temanya tidak bisa mengerjakan PR yang diberikan disekolah oleh gurunya tanpa ragu Hepi selalu menolong temanya jika temanya tidak bisa mengerti mengerjakanya.
(1.4) Hepi melihat Zen disepak maling. Dia dengan nekat segera 
menerjang ke tengah, mencoba melindungi

Zen dari pukulan susulan. Tapi dia di hadang oleh sesosok berbaju hitam. "Eh Ada anak kecil lagi mati wa'ang," geram orang itu menebaskan ke lehernya (AR: 289)

Kutipan 1.4 menggambarkan Hepi menolong Zen dari terjangan maling dengan memberikan pukulan, tapi dia di hadang oleh orang lain. Bentuk tolong-menolong Hepi ialah merusaha melindungi Zen agar tidak terkena pukulan oleh maling.

(1.5) Di disinilah rizki Hepi dan kawan-kawannya terbuka. Kakek yang punya banyak pohon durian minta tolong kepada mereka bertiga untuk jadi pembantunya dalam menjual durian. Tugas mereka adalah mencari pembeli, membawa pembeli dan mencari orang yang bisa mengumpulkan durian kebun untuk di bawa ketepi jalan (AR: 301)

Kutipan 1.5 menggambarkan

Hepi dan teman-temannya diminta kakek untuk membantunya dalam menjual durian tidak hanya menjual Hepi juga mencari orang yang bisa mengumpulkan dan membawa durian ketepi jalan . Bentuk tolong menolong yang dilakukan Hepi adalah membantu kakennya untuk menjualkan durian dan mencari orang untuk membawa durian ketepi jalan.
(1.6) Hepi tepuk lagi kantongnya, terasa padat dan berdenting-denting. Dia memutuskan untuk memberikan tabunganya ini untuk operasi Pendeka Luko. Biarlah dia mulai mengumpulkan uang kembali untuk pulang (AR: 351)

Kutipan 1.6 menggambarkan uang yang telah ia tabung untuk berangkat ke Jakarta tidak jadi digunakan karena Hepi merasa ada yang lebih membutuhkan di bandingkan diirinya yaitu Pendeka Luko, jadi dia memutuskan untuk memberikan uang tabunganya kepada Pendeka Luko. Bentuk tolongmenolong yang Hepi lakukan ialah memberikan tabunganya kepada Pendeka Luko untuk operasi mata.

(1.7) Seharian kerja Hepi hanya menasehati Zen karena telah membuat Ibu Ibet ketakutan. Yang membuat Hepi naik darah Zen merasa tak berhak diomeli (AR: 89)

Kutipan

menggambarkan Hepi yang sedang menasehati Zen karena telah membuat Ibu Ibet ketakutan. Dan mengingatkan bahwa yang Zen lakukan itu salah agar tidak mengualingi lagi. Bentuk tolongmenolong yang dilakukan Hepi adalah mengingatkan kepada Zen bahwa yang ia lakukan itu salah dan dapat membahayakan orang lain.

(1.8) "Kek, aku sebetulnya sedang belajar dari kultum kakek tempo hari. Kakek bilang sebaiknya 
tangan kita selalu di atas tangan yang menolong. Kami melihat Mak Tuo Ro situ sudah tua dan bekerja mengurus lapaunya. Kasihan sekali kami menawarkan bantuan dan dia setuju. Jadi kami Cuma membantu, Kek (AR: 93)

Kutipan 1.8 menggambarkan kabar Hepi membantu Mak Tuo Ros sampai ke kuping kakek dan neneknya. Kakek tampak marah karena Hepi di kampung bukan untuk menjadi pembantu melainkan belajar. Tapi Hepi memberikan penjelasan bahwa Hepi dengan iklas membantu Mak Tuo Ros karena kasihan melihat Mak Tuo Ros kelelahan yang mengurus lapaunya sendirian. Bentuk tolong menolong yang dia lakukan Hepi mencoba meyakinkan kakenya bahwa tolong-menolong itu perlu apalagi dia melihat Mak Tuo Ros hanya sendirian.

Tolong-menolong berarti membantu agar dapat melakukan sesuatu. Tolong-menolong sangat dibutuhkan setiap manusia, biasanya tolong-menolong dilakukan lebih dari satu orang manusia. Orang yang memiliki sikap tolong-menolong berarti orang yang hidup bermasyarakat. Tokoh Hepi memiliki sikap tolong-menolong berarti orang yang baik terhadap masyarakat lainya. Tokoh Hepi sangat cepat berinteraksi dengan manusia lain dan memiliki rasa solidaritas yang tinggi terhadap manusia lainya. Terlihat saat tokoh Hepi membantu keluarganya, teman-temanya dan mayarakat disekitarnya. Tokoh Hepi termasuk anak yang pintar di sekolahnya tak jarang Hepi membantu temantemanya untuk mengjarinya mengerjakan PR yang diberikan gurunya.

\section{KESIMPULAN}

Berdasarkan temuan penelitian dan pembahasan yang telah dijelaskan pada bagian terdahulu, maka dapat disimpulkan beberapa hal sebagai berikut Nilai etika tolong-menolong yang terdapat di dalam novel Anak Rantau karya A. Fuadi tergambar sikap Hepi yang memiliki sikap tolong menolong yang baik terhadap masyarakat. Hidup dalam masyarakat tolong menolong sangat penting guna menumbuhkan rasa memiliki dan keakraban antar masyarakat lainnya karena tolongmenolong dibutuhkan oleh setiap manusia seperti yang dilakukan oleh tokoh Hepi. Tokoh Hepi sangat cepat berinteraksi dengan manusia lainnya serta memiliki sikap tolongmenolong dengan orang lain. Terlihat tokoh Hepi membantu Kakeknya pada saat membutuhkan, temantemanya dari mara bahaya, bahkan Hepi menyelamatkan kampungnya sendiri agar terhindar dari narkoba.hal ini terlihat dari 8 kutipan. Saran yang ingin penulis sampaikan dari hasil penelitian novel Anak Rantau karya A. Fuadi sebagai berikut:

1. Disarankan guru bahasa Indonesia dapat meningkatkan apresiasi sastra sehingga pembelajaran sastra lebih menarik dan diminati serta dapat dipergunakan juga sebagai masukan dalam memahami 
unsur-unsur ekstrinsik terhadap karya sastra terutama novel.

2. Disarankan terhadap sastrawan agar dapat menyuguhkan karyas sastra berbentuk novel yang didalamnya terdapat banyak nilai etika.

3. Disarnkan bagi pembaca nilainilai etika yang terdapat dalam novel Anak Rantau karya A. Fuadi dapat dijadikan pedoman dalam hidup

4. Disarankan penelitian ini dapat dijadikan acuan bagi peneliti berikutnya yang akan mengkaji objek peneltian yang sama maupun objek yang berbeda.

\section{DAFTAR PUSTAKA}

Abdullah, Yatimin, 2006. Pengantar Studi Etika. Jakarta : Raja Grafindo Persada.

Antilan. Purba 2012. Sastra Indonesia Kontemporer. Yogyakarta: Graha Ilmu.Damayanti, 2013. Sastra Indonesia. Yogyakarta: Araska.

Dewajati, Cahyaningrum. 2015. Sastra Populer Indonesia. Yogyakarta: Gajah Mada University Press.

Endraswara, Suwardi. 2011. Metode Pembelajaran Drama. Yogyakarta: CAPS.

Rohmansyah, Alfian. 2014. Studi dan Pengkajian Sastra. Yogyakarata: Graha Ilmu.

Rafiek, 2010. Teori Sastra Kajian Teori dan Praktik. Bandung: Rafika Aditama.

Siswantoro. 2010. Metode Penelitian Sastra. Yogyakarta: Pustaka Belajar.
Susanto, Dwi. 2016. Pengantar Kajian Sastra. Yogyakarta: CAPS

Gunawan. 2014. Analisis Nilai Etika Tokoh Keenan dalam Novel Perahu Kertas Karya Dewi Lestari.

Nainggolan, Rehnah. 2012. Analisis Nilai Etika Terhadap Tokoh Keke dalam Novel Surat Cinta Untuk Tuhan karya Agnes Davona.

Lestari, Stani Kusuma. 2010. Studi Analisis Wacana Penerapan Etika Moral pada Program Liputan 6 Petang Surya Citra Televisi (SCTV).

Astrini, Diyah Retno. 2014. NilaiNilai Moral dalam Tokoh Utama dalam Novel Perahu Kertas Karya Dewi Lestari. 